\title{
Analysis of Contextual Problem Solutions, Mathematical Sentences, and Misconceptions of Pre-Service Mathematics Teachers
}

\author{
Aziz llhan ${ }^{1 *}(\mathbb{D})$ M. Faysal Akin ${ }^{2}$ (D)
}

${ }^{1}$ Inonu University, TURKEY

${ }^{2}$ Dicle University, TURKEY

*Corresponding Author: aziz.ilhan@inonu.edu.tr

Citation: Ilhan, A., \& Akin, M. F. (2022). Analysis of Contextual Problem Solutions, Mathematical Sentences, and Misconceptions of Pre-Service Mathematics Teachers. International Electronic Journal of Mathematics Education, 17(1), em0666. https://doi.org/10.29333/iejme/11470

ARTICLE INFO

Received: 22 Oct. 2021

Accepted: 29 Nov. 2021

\begin{abstract}
The present study aimed to analyses the context-based problem solutions of pre-service mathematics teachers, their mathematical sentences formation skills and misconceptions. Thus, the participating pre-service mathematics teachers were asked to solve context-based problems, form mathematical sentences formation, predict misconceptions that they could experience in solving these problems and assess the related problems based on Benckert's (1997) contextual learning principles. Furthermore, the views of pre-service mathematics teachers on contextual problems were also obtained. Thus, the study was designed as a mixed-method case study that included both quantitative and qualitative data. Context-Based Problem Evaluation Form and a structured interview form developed by the authors were used as data collection instruments. Study participants included 114 (82 females, 32 males) pre-service mathematics teachers. Analysis of the study data demonstrated that preservice mathematics teachers were above-average in solving contextual problems and mathematical sentences formation, their misconceptions were below-average, and there were no significant differences between the above-mentioned study variables based on gender variable; however, there were significant differences based on student department, and mean participant score was above-average based on Benckert's principles. Furthermore, the views of pre-service mathematics teachers on contextual problems were determined and the conceptual and structural differences between the questions were analyzed.
\end{abstract}

Keywords: evaluation of context-based problems, mathematical sentences formation, misconception, preservice mathematics teachers

\section{INTRODUCTION}

\section{Context and Contextual Learning}

Learning occurs in real-life situations and with unique contexts established through rich context-centered life situations (Yurdakul, 2021). Context is defined as a term reflecting concepts through other elements by joining or integrating with the help of other elements (Baltacı \& Baki, 2017). With the emergence of the concept of context, the concept of contextual learning was introduced in the literature and different descriptions of contextual learning were published. Contextual learning was described as the use of various daily life situations in the instruction of the course content (Glynn \& Koballa, 2005). Berns and Erickson (2001) also described the concept of contextual learning as a learning process that aimed to determine the life contexts, which help the learners to learn. Accordingly, contextual learning could be defines as a learning method where learners are very active in the learning process and the teacher includes daily-life contexts in the instruction process. Contextual learning was replaced by context-based learning over time, and context-based learning descriptions were introduced in the literature. Context-based learning was described as an important opportunity to learn science using meaningful contexts and content (Stinner, 1980). Sozbilir et al. (2007) defined context-based learning as the teaching of scientific concepts to students through contexts created with events selected from daily life. Based on these definitions, context-based learning could be described as the association of the events or situations encountered in daily life or social issues with the content of the course, and transformation of these associations into learning opportunities. Thus, context-based problems that include adequate vital contexts for the students, allow the student feel that the problem is directly related to daily life, confront the students with problems that they can solve using their cognitive skills, and terminated as a qualitative question, allowing the students to prove the problem quantitatively (Tekbiyik \& Akdeniz, 2010). Benckert (1997) researched context-based learning and defined the context-based learning approach in seven items. The items are as follows: (1) Each problem statement is a story in which the learner is the main character. (2) Each problem statement should include a plausible motivation for the learner to solve the problem. (3) The objects in each problem 
statement should be based on real-life. (4) The problem should not be solved in one step by placing the necessary numbers into a formula. (5) The problem statement should not include more information than necessary. (6) The problem statement should not explicitly state the unknown variable (7) Assumptions need to be made to solve the problem.

\section{Mathematical Problems}

Schoenfeld (2006) suggests that learners should face as many different types of problems as possible in order to choose the appropriate strategy in teaching processes. Therefore, it is necessary to know the relationship between the concepts of questions, exercises and problems. In order for a problem to be expressed as a problem for the individual, it must be new for the individual who will solve it. Problem an obstacle to an individual's facilities to achieve his/her goals (Bingham, 1998). In general, a problem is a situation where the individual encounters the problem for the first time and needs to solve it and a way to solve the problem is not known, but that the individual could solve it using his/her knowledge and skills (Olkun \& Toluk, 2009). It is important to know the concept of problem-solving as well as the concept of the problem. Problem-solving is the process of doing what is necessary to eliminate an unknown or unclear situation (Posamentier \& Krulik, 2008). Problem solving was described as a tool used by an individual in order to meet the requirements of an unusual new situation and constructed by previous knowledge and skills (Toluk \& Olkun, 2002). An individual who can solve problems becomes aware of his/her abilities and improves himself/herself, this individual does not expect others to solve the problems he/she experiences and reaches his/her own solutions through thinking and questioning (Yazici, 2014). The main property that distinguishes mathematical problems from other daily life problems is the use of mathematical knowledge in solving these problems (Hiebert, 1986). Problems are utilized in mathematics courses to draw attention to the topic of instruction, motivate the students, allow them to recognize the learned knowledge, and evaluate the students (Posamentier \& Krulik, 2016). In addition to the fact that problem solving is at the core of the topics in MoNE (2018) mathematics curriculum, it aims to develop problem solving skills in general based on the specific objectives of the program.

\section{Misconceptions}

Baki and Bell (1997) defined misconception as knowledge that was accumulates as a result of personal experiences, contradicts scientific facts, and prevents the instruction and learning of concepts that were evidenced by science. Ubuz (1999) described misconception as the perception of the concepts different from the scientifically accepted definition by the students. Yagbasan and Gulcicek (2003) described misconception as knowledge that is not consistent with the facts and stated that wrong explanations, wrong questions or excessive generalizations are among the causes of misconception. Ilyas and Saeed (2018) defined misconceptions as barriers to students' learning. According to Eryilmaz and Surmeli (2002), in order to accept student ideas as misconceptions, the student's ideas should not be consistent with the real science, the student should come up with reasons or explanations to defend his/her wrong ideas and be sure about his/her explanations. Learners could use the concepts to turn comprehensive knowledge into smaller and available units (Senemoglu, 2018). Therefore, it was considered very important to identify the misconceptions of students on basic concepts (Ayvaci \& Coruhlu, 2009). For accurate and permanent instruction of knowledge, it is important to recognize the misconceptions in advance to eliminate the preexisting misconceptions and prevent the creation of new ones (Atilboz, 2004). In order for the training to be applied to eliminate the misconceptions to be successful, the misconceptions must first be correctly identified (Costu et al., 2007). Ozbellek (2003) reported that misconceptions constitute a major obstacle to meaningful learning, and especially the failure to eliminate permanent mistakes over time leads to significant difficulties in achieving the objectives of mathematics instruction. Keskin et al. (2017) stated that educators should transform misconceptions into accurate scientific knowledge, despite the fact that the misconceptions are resistant to correction. According to Aydogan and Gelbal (2017), misconception is the difference between the perception of a concept and scientific definition of the same concept due to certain preconseptions that are resistant to change. According to Bahar (2003), it is difficult to correct misconceptions that are different when compared to the current scientific knowledge. According to Dikmenli et al. (2009), uncorrected misconceptions could lead to further misconceptions that could remain constant for long years. Thus, misconceptions are considered different from wrong answers given by mistake or due to lack of knowledge. If an explanation and assurances are provided with the mistake, this could be considered as a misconception (Eryilmaz \& Sürmeli, 2002).

\section{Theoretical Framework and Literature Review}

The theoretical framework of the study is constituted by context-based learning, mathematical problems, and misconceptions. It was observed that international studies on context-based learning included mostly conceptual and experimental studies (Benckert, 1997; Bennett et al., 2005a, 2005b; Choi \& Johnson, 2005; De-Jong, 2006; Fechner, 2009; Glynn \& Koballa, 2005; Khumalo, 2009; King, 2012; Lubben et al., 1996; Ryve \& Hemmi, 2019; Selvianiresa \& Prabawanto, 2017; Whitelegg \& Parry, 1999), while a higher number of domestic studies were experimental in Turkey (Acar \& Yaman, 2011; Baltaci \& Baki, 2017; Derman \& Badeli, 2017; Elmas \& Geban, 2016; Olkun \& Toluk, 2009; Yazici, 2014). A review of the studies on problem solving demonstrated that studies included conceptual and experimental national studies on the development of problem solving skills domestic (Aylar, 2017; Gurbuz \& Guder, 2016; Ozsoy \& Ataman, 2009) and international (Cai, 2003; Cheany \& Ingebritsen, 2005; Harskamp \& Suhne, 2007; Heller \& Hollabaugh, 1992; Passolunghi et al., 2019; Pugalee, 2001). It was observed that international (Abramovich \& Ehrlich, 2007; Almong \& Ilany, 2012; Noll \& Hancock, 2015; Ryan \& Williams, 2000) and national (Ayvaci \& Coruhlu, 2009; Costu et al., 2007; Senemoglu, 2018; Yagbasan \& Gulcicek, 2003) studies on misconception included mostly experimental. In addition, gender and class variables in mathematics education are gaining importance in national or international reports and researched in scientific studies. In addition, the importance of mixed education is increasing and cross-sectional information can be obtained with the differences between the classes (Ernest et al., 2019; MoNE, 2018; PISA, 2018; Zhu et al., 2018). When the studies in the literature are assessed, this study in which the solutions of pre-service mathematics teachers related to contextbased problem statements were evaluated according to Benckert's principles, the conceptual and structural differences between 
the questions were analyzed by addressing the main ideas of the aforementioned problems, mathematical sentences formation and the misconceptions were researched, is thought as being unique and contribute to the field.

\section{The Aim of Study and Sub-problems}

The present study aimed to analyses the context-based problem solutions of pre-service mathematics teachers, their mathematical sentences formation skills and misconceptions. Thus, the following research sub-problems were determined related to the problem-solving skills of pre-service mathematics teachers:

1. Is there a difference between the problem-solving skills of pre-service mathematics teachers based on gender and grade variables?

2. Is there a difference between the mathematical sentences formation of pre-service mathematics teachers based on gender and grade variables?

3. Is there a difference between the misconceptions of pre-service mathematics teachers based on gender and grade variables?

4. What are the views of pre-service mathematics teachers based on Benckert's concept-based learning principles?

5. How the pre-service mathematics teachers assess conceptual and structural differences between their ideas and the questions?

\section{METHODOLOGY}

\section{The Research Model}

The present study was conducted in mixed design since both quantitative and qualitative data were collected. In the study, quantitative data were examined in terms of gender and class level by using a causal comparison research design, one of the relational survey models. The causal comparison research design is used to determine whether the independent variable makes a difference in its measurements on the dependent variable consisting of different categories (Gay et al., 2006). The study aimed to analyze the context-based problem solutions of pre-service mathematics teachers, their mathematical sentences formation and misconceptions; thus, it was designed as a case study. The main objective in a case study is to conduct a detailed research about a case or concept and to present the case as is (Buyukozturk et al., 2016). Thus, mathematical problem-solving skills, and mathematical sentences formation skills of pre-service mathematics teachers were determined, and their misconceptions about these problems were analyzed. Furthermore, the mixed-method exploratory design was adopted, and the pre-service mathematics teachers were allowed to assess the conceptual and structural differences between their ideas and the questions. The reason for choosing this method is to render the obtained quantitative data by explaining them using qualitative data.

\section{The Study Participants}

The study participants included 114 ( 82 female and 32 male students) pre-service mathematics teachers attending the faculty of education in Turkish university located in Southeastern Anatolia region. Convenience sampling method was used in the study since one of the authors was a student and an employee in mathematics education department in the university. The study was conducted with freshmen, sophomore, junior and senior students in the mathematics education department. Convenience sampling method entails selection of the sample from an easily accessible population due to time, money and labor constraints (Buyukozturk et al., 2016).

\section{Data Collection Instruments}

\section{Context-based problem evaluation form (CPEF)}

As a result of the literature review, the CPEF that included 15 questions, eight of which were related to the research problems and seven of which were related to Benckert's (1997) context-based problem principles, was developed. During the development of the questionnaire, attention was paid to ensure that there were no questions that could be answered with a yes or a no, and the questions did not include any expressions or concepts that may lead to misconceptions. To determine the construct validity of the form, four faculty members in the field of mathematics education were consulted. Based on the expert feedback, it was decided that one problem sentence was not adequate and it was removed from the form. The draft form was then applied to seventeen pre-service teachers, who were not included in the main study sample. In this process, grammar mistakes and intelligibility problems were corrected, and the form was finalized to include seven open-ended questions and seven questions with 3-point Likert-type responses. The final form created was applied to the entire research sample (see Appendix 1).

\section{Structured interview form (SIF)}

The SIF including five questions was developed based on the literature review. During the development of the questionnaire, attention was paid to ensure that there were no questions that could be answered with a yes or a no, and the questions did not include any expressions or concepts that may lead to misconceptions. To determine the construct validity of the form, four faculty members in the field of mathematics education were consulted. Based on the expert feedback, it was concluded that two questions were not adequate and these questions were removed from the form. The draft form was then applied to seventeen prospective teachers who were not included in the main study sample. In this process, grammar mistakes and intelligibility 
problems were corrected, and the form was finalized to include three open-ended questions. The final form created was applied to the entire research sample (see Appendix 2).

\section{Data analysis}

The quantitative study data were analyzed with descriptive statistics, t-test, ANOVA, LSD test, Cohen's $f$, and Cohen's $d$ effect sizes. In a study, the effect size (Cohen's $d$ ) calculated for paired groups is interpreted as follows: If the value is $0.20-0.49$, the effect size is considered small, $0.50-0.79$, the effect size is considered moderate and 0.80 or above, the effect size is considered high (Cohen, 1988). To calculate the effect size in the analysis of variance between multiple groups, Cohen's $f$ is used. When interpreting Cohen's $f$, the effect size is considered small when the value is $0.10-0.24$, the effect size is considered moderate when the value is $0.25-0.39$, the effect size is considered high when the value is 0.40 or higher (Cohen, 1988). While evaluating the quantitative data in the study, 6 problem and mathematical sentences; correct answers were scored as " 1 " and incorrect answers as " 0 ". In addition, the misconceptions that may occur with these problems; correct answers were scored as " 1 " and incorrect answers as "0". Qualitative study data were analyzed with the content analysis method. Content analysis allows to combine and organize similar data based on the topic and present this data using certain themes and concepts (Yildirim \& Simsek, 2013). Thus, the raw SIF data was listed, edited and coded for analysis. To comply with ethical principles, each participant was assigned a code name such as $\mathrm{K} 1, \mathrm{~K} 2, \ldots$ The data codes were determined, correlated codes were identified, and the themes that included the codes with similar meanings were developed. To ensure the reliability of coding and the theme development, the data were coded independently by both authors and the agreement between these codes was determined. It was found that two codes assigned by the authors were different. Thus, these different codes were again submitted for the analysis of the two experts. The codes were redeveloped based on the expert feedback and the codes were finalized for analysis. Furthermore, to determine the reliability of the qualitative data, Miles and Huberman's (1994) agreement ratio formula was used. Agreement ratio was calculated with the reliability = agreements/(agreements + disagreements) $\times 100$ formula. It was suggested that a case is reliable when coding reliability is $90 \%$ or above (Miles \& Huberman, 1994). Accordingly, since the consulted experts changed the category of only two statements, the Agreement Rate of the form was calculated as $(24 / 24+2) \times 100=92.30 \%$.

\section{FINDINGS}

The t-test results on the differences between context-based problem solutions of pre-service mathematics teachers based on the gender variable are presented in Table 1.

Table 1. The t-test results on the differences between context-based problem solutions based on the gender variable

\begin{tabular}{cccccccc}
\hline Gender & $\mathbf{N}$ & $\overline{\mathbf{X}}$ & \% & sd. & df. & t & p \\
\hline Female & 82 & 3.476 & 57.933 & 1.239 & \multirow{2}{*}{112} & \multirow{2}{*}{-1.375} & 0.172 \\
\hline Male & 32 & 3.843 & 64.050 & 1.393 & & & \\
\hline
\end{tabular}

According to Table 1, it can be said that both male and female pre-service mathematics teachers are successful in problemsolving. Also, this data demonstrated that male pre-service mathematics teachers were more successful in solving problems when compared to female pre-service mathematics teachers; however, the difference was not significant $[t=-1.375, p>0.05]$. After the differences between problem-solving scores based on the gender variable were analyzed, it was analyzed whether the differences between problem-solving scores were significant based on the class variable. The ANOVA findings on the differences between problem-solving scores based on the class variable are presented in Table 2.

Table 2. ANOVA findings on the differences between context-based problem solutions based on the class variable

\begin{tabular}{|c|c|c|c|c|c|c|c|c|c|}
\hline & & $X^{2}$ & df. & $\mathbf{F}$ & $\mathbf{p}$ & Cohen'sf & Class & $\mathbf{p}$ & Cohen's d \\
\hline \multirow{3}{*}{$\begin{array}{l}\text { Problem- } \\
\text { solving }\end{array}$} & Between groups & 17.109 & 3 & \multirow{3}{*}{3.675} & \multirow{3}{*}{0.014} & \multirow{3}{*}{0.316} & \multirow{3}{*}{$\begin{array}{l}1>2 \\
1>3\end{array}$} & \multirow{3}{*}{$\begin{array}{l}0.019 \\
0.003\end{array}$} & \multirow{3}{*}{$\begin{array}{l}0.624 \\
0.733\end{array}$} \\
\hline & In group & 170.681 & 110 & & & & & & \\
\hline & Total & 187.789 & 113 & & & & & & \\
\hline
\end{tabular}

A review of Table 2 demonstrated that there was a significant difference between mean problem-solving scores of the preservice teachers based on class level $(p=0.014<0.05)$. The calculated effect size indicated that the differences based on class were moderate (Cohen's $f=0.316$ ). To determine whether there were differences between each class level, LSD test was conducted and it was determined that there were significant differences between the scores of freshmen and sophomores $(p=0.019<0.05)$ and freshmen and juniors $(p=0.003<0.05)$ favoring the freshmen $(\bar{X}$ freshmen $=4.096, \bar{X}$ sophomore $=3.321, \bar{X}$ junior $=3.107, \bar{X}$ senior $=$ 3.740). Review of the effect sizes between the classes where the difference was significant demonstrated that there was a moderate effect between freshmen and sophomores and between freshmen and juniors (Cohen's $d$ : fresh.-soph. $=0.624$, fresh.-junior $=$ 0.733). After the analysis of the ANOVA findings on problem-solving skills based on the class variable, mathematical sentences formation t-test findings were analyzed based on the gender variable and the results are presented in Table 3.

Table 3. The t-test results on the differences between mathematical sentences formation based on the gender variable

\begin{tabular}{cccccccc}
\hline Gender & $\mathbf{N}$ & $\overline{\mathbf{X}}$ & $\mathbf{0}$ & $\mathbf{s d .}$ & df. & $\mathbf{t}$ & $\mathbf{p}$ \\
\hline Female & 82 & 3.902 & 65.033 & 0.910 & \multirow{2}{*}{112} & \multirow{2}{*}{-1.064} & \multirow{2}{*}{0.289} \\
\hline Male & 32 & 4.125 & 68.750 & 1.211 & & & \\
\hline
\end{tabular}


According to Table 3, male pre-service mathematics teachers were more successful when compared to female pre-service mathematics teachers in mathematical sentences formation, however, the difference was not significant $[t=-1.064, p>0.05]$. After the differences between mathematical sentences formation were analyzed based on the gender variable, the significance of these differences based on the class variable was investigated. The ANOVA findings on the differences between mathematical sentences formation scores based on the class variable are presented in Table 4.

Table 4. ANOVA findings on the differences between mathematical sentences formation based on the class variable

\begin{tabular}{|c|c|c|c|c|c|c|c|c|c|}
\hline & & $X^{2}$ & df. & $\mathbf{F}$ & $\mathbf{p}$ & Cohen'sf & Class & $\mathbf{p}$ & Cohen's d \\
\hline \multirow{3}{*}{$\begin{array}{c}\text { Mathematical } \\
\text { sentences } \\
\text { formation }\end{array}$} & Between groups & 17.518 & 3 & \multirow{3}{*}{3.732} & \multirow{3}{*}{0.013} & \multirow{3}{*}{0.319} & \multirow{3}{*}{$\begin{array}{l}1>2 \\
2<4\end{array}$} & \multirow{3}{*}{$\begin{array}{l}0.002 \\
0.042\end{array}$} & \multirow{3}{*}{$\begin{array}{l}0.786 \\
0.561\end{array}$} \\
\hline & In group & 103.341 & 110 & & & & & & \\
\hline & Total & 113.860 & 113 & & & & & & \\
\hline
\end{tabular}

A review of Table 4 demonstrated that there was a significant difference between mean mathematical sentences formation scores of the pre-service teachers based on class level $(p=0.013<0.05)$. The calculated effect size indicated that the differences between the class levels were moderate (Cohen's $f=0.319)$. To determine the class levels where there were differences, LSD test was conducted and it was determined that there were significant differences between freshmen and sophomores $(p=0.02<0.05)$ and sophomores and seniors ( $p=0.042<0.05$ ) favoring the freshmen and seniors ( $\bar{X}$ freshmen $=4.354, \bar{X}$ sophomore $=3.535, \bar{X}$ junior $=3.857, \bar{X}$ senior $=4.074$ ). Review of the effect sizes between the classes where the difference was significant demonstrated that there was a moderate effect between freshmen and sophomores and between sophomores and seniors (Cohen's $d$ : fresh.-soph. = 0.786 , soph.-senior $=0.561$ ). After the analysis of the results of the ANOVA conducted on mathematical sentences formation based on the class variable, t-test results on misconceptions were analyzed based on the gender variable and the findings are presented in Table 5.

Table 5. The t-test results on the differences between misconceptions based on the gender variable

\begin{tabular}{cccccccc}
\hline Gender & $\mathbf{N}$ & $\overline{\mathbf{X}}$ & $\%$ & $\mathbf{s d .}$ & df. & t & p \\
\hline Female & 82 & 0.426 & 42.680 & 0.069 & \multirow{2}{*}{112} & \multirow{2}{*}{1.162} & \multirow{2}{*}{0.248} \\
\hline Male & 32 & 0.281 & 28.130 & 0.092 & & & \\
\hline
\end{tabular}

A review of Table 5 demonstrated that male pre-service mathematics teachers lower number of misconceptions when compared to female pre-service mathematics teachers; however, the difference was not significant $[t=1.161, p>0.05]$. After the analysis of the differences between misconceptions based on the gender variable, whether there were differences based on the class variable was investigated. The findings are presented in Table 6.

Table 6. ANOVA findings on the differences between misconceptions based on the class variable

\begin{tabular}{|c|c|c|c|c|c|c|c|c|c|}
\hline & & $X^{2}$ & df. & $\mathbf{F}$ & $\mathbf{p}$ & Cohen'sf & Class & $\mathbf{p}$ & Cohen's d \\
\hline \multirow{3}{*}{ Misconceptions } & Between groups & 5.118 & 3 & & & & $1<3$ & 0.001 & 1.063 \\
\hline & In group & 35.900 & 110 & 5.227 & 0.002 & 0.377 & $2<3$ & 0.001 & 0.856 \\
\hline & Total & 41.018 & 113 & & & & $3<4$ & 0.008 & 0.641 \\
\hline
\end{tabular}

A review of Table 6 demonstrated that there was a significant difference between mean misconception scores of the preservice teachers based on class level $(p=0.002<0.05)$. The calculated effect size indicated that the differences were moderate based on class levels (Cohen's $f=0.377$ ). LSD test was conducted to determine the class levels between which there were differences, and it was determined that there were significant differences between freshmen and juniors $(p=0.001<0.05)$, sophomores and juniors $(p=0.001<0.05)$, and juniors and seniors $(p=0.008<0.05)$ favoring the juniors $(\bar{X}$ freshmen $=0.258$, $\bar{X}$ sophomore $=0.214, \bar{X}$ junior $=0.750, \bar{X}$ senior $=0.333$ ). Review of the effect sizes between the class levels where the difference was significant demonstrated that the effect was high between freshmen and juniors, and between sophomores and juniors (Cohen's $d$ : fresh.-junior. $=1.063$, soph.-junior $=0.856$ ) and the effect was moderate between juniors and seniors (Cohen's $d$ : junior-senior $=$ 0.641). After the analysis of the findings of the ANOVA conducted on misconceptions based on the class variable, the views of preservice mathematics teachers on the problems presented in the study based on Benckert (1997) principles were analyzed and the findings are presented in Table 7.

Table 7. The mean assessment scores of pre-service mathematics teachers

\begin{tabular}{|c|c|c|c|c|}
\hline & $\mathbf{N}$ & $\mathbf{X}$ & $\%$ & sd. \\
\hline 1. Problem is a story where the student is a protagonist. & \multirow{8}{*}{114} & 2.279 & 75.966 & 0.559 \\
\hline 2. Problem includes a reason that would motivate the student to solve the problem. & & 2.352 & 78.400 & 0.562 \\
\hline 3. The objects used in the problem were selected from real-life. & & 2.671 & 89.033 & 0.480 \\
\hline 4. The problem cannot be solved by assigning certain numbers to an equation. & & 2.032 & 67.733 & 0.519 \\
\hline 5. Problem includes more information than required for the solution. & & 1.764 & 58.800 & 0.522 \\
\hline 6. The unknown variable was not clearly stated in the problem. & & 1.808 & 60.266 & 0.623 \\
\hline 7. Certain assumptions are required to solve the problem. & & 2.130 & 71.000 & 0.591 \\
\hline General & & 2.148 & 71.600 & 0.550 \\
\hline
\end{tabular}


In scientific studies conducted with five-point Likert-type measuring instruments based on the five columns-four intervals approach, 4/5=0.8, 1.00-1.79 range corresponds to "I Completely Disagree", 1.80-2.59 range corresponds to "I Disagree", 2.60-3.39 range corresponds to "I do not know", 3.40-4.19 range corresponds to "I agree" and 4.20-5.00 range corresponds to "I completely agree" (Banoglu and Bas, 2012). Thus, since the present study was conducted with a 3-point Likert type scale based on the threecolumn, 2-range approach; 2/3=0.66, 1.00-1.65 range corresponded to "I disagree", 1.66-2.31 range corresponded to "I do not know," and 2.32-3.00 range corresponded to "I Agree." Based on Benckert's 2nd (78,400\%) and 3rd (89,033\%) principles, the evaluation scores of the pre-service mathematics teachers corresponded to "I Agree," while their evaluation scores for all other principles and their overall score corresponded to "I do not know" option. Furthermore, the scores for each principle and overall scores were above average. The qualitative study data were analyzed with the content analysis method. Themes, codes, and frequencies were determined based on the obtained views. Based on the responses of pre-service mathematics teachers to the questions in CPEF, 3 themes were determined: "Cognitive skills", "Change in ideas" and "Conceptual or structural similarity". The findings are presented in Table 8.

Table 8. CPEF themes, codes and frequency distributions

\begin{tabular}{|c|c|c|}
\hline Themes & Codes & f \\
\hline \multirow{6}{*}{ Cognitive skills } & Developing solution strategies & 33 \\
\hline & Associating the problems with daily life & 28 \\
\hline & Developing different thinking methods & 22 \\
\hline & Developing operational skills & 16 \\
\hline & Attention measurement & 10 \\
\hline & Determination of misconceptions & 5 \\
\hline \multirow{3}{*}{ Change in views } & Complete change in views & 54 \\
\hline & Partial change in views & 41 \\
\hline & No change in views & 19 \\
\hline \multirow{4}{*}{ Conceptual or structural similarities } & There are no differences between the questions & 37 \\
\hline & There are differences between all questions & 34 \\
\hline & Questions $1-3$ and 6 are similar & 29 \\
\hline & Questions 1-5 and 3-6 are similar & 14 \\
\hline
\end{tabular}

In the research, firstly, the pre-service mathematics teachers were asked, "What do you think are the cognitive skills obtained in the CPEF study?" question has been asked. Six codes were identified in the "cognitive skills" theme that was determined based on the answers given to this question. The final codes included "Developing solution strategies" $(f=33)$, "Associating the problems with daily life" ( $f=28)$, "Developing different thinking methods" ( $f=22)$, "Developing operational skills" ( $f=16)$, "Attention measurement" $(f=10)$, and "Determination of misconceptions" $(f=5)$. The sentences mentioned by the pre-service mathematics teachers for each code in this theme were as follows:

Assumptions are made for the solution of the problem at the problem-solving stage (K45).

It encourages students to think, solve problems and improves concentration by adapting the problems to daily life (K41).

They aim for versatile thinking. The questions are important for the comprehension of the topic (K48).

A division with the same numbers can be solved in several ways (K12).

The aim was to measure attention, determine selective perception, and assess the perspective (K6).

The aim was to determine the misconceptions in given problem sentences and to make the problem sentences more comprehensible by the students (K108).

In the study, the second question was "Did your views on the main theme of the study change after the CPEF application? Explain the reasons." Three codes were identified in the "change in views" theme that was determined based on the answers given to this question. The final codes included "Complete change in views" ( $f=54)$, "Partial change in views" $(f=41)$, and "No change in views" ( $f=19)$. The sentences mentioned by the pre-service mathematics teachers for each code in this theme were as follows:

They changed; I did not think that the concepts used in a question could change the answer to the question (K9).

In some cases, they changed. I thought the stories included the same solution before the study (K55).

It did not have a significant effect since I have encountered similar questions before (K68).

In the study, the last question asked to the pre-service mathematics teachers was "Are there differences between the questions $1,3,5$, and 6 based on CPEF (Please also indicate the questions that had conceptual or structural similarities)." Four codes were identified in the "conceptual or structural similarities" theme determined based on the answers given to this question. The resulting codes included "There are no differences between the questions" ( $f=37$ ), "There are differences between all questions" $(f=34)$, "Questions 1-3 and 6 are similar" ( $f=29)$, and "Questions 1-5 and 3-6 are similar" $(f=14)$. The sentences stated by the preservice mathematics teachers in each code related to this theme were as follows: 
No, there are none, just storytelling is different (K67).

Although the same numbers were used in all, the constructs of the questions were different (K58).

Questions 1, 3, and 6 are structurally similar. Question 5 is structurally different (K85).

There is a structural similarity between questions 1 and 5 . There is a structural similarity between questions 3 and 6 (K25).

\section{CONCLUSIONS AND DISCUSSION}

Benckert (1997) published seven principles associated with context-based problems. The present study aimed to analyze the context-based problem-solving skills of pre-service mathematics teachers, their mathematical sentences formation skills and misconceptions. Thus, pre-service mathematics teachers were asked to solve context-based mathematical problems, mathematical sentences formation, estimate possible misconceptions when solving these problems, and evaluate the abovementioned problems based on Benckert's (1997) context-based learning principles. Furthermore, the views of pre-service mathematics teachers about context-based problems were also obtained. The results demonstrated that the context-based problem-solving scores of male pre-service mathematics teachers were higher when compared to female pre-service mathematics teachers; however, the difference was not significant. At the same time, results demonstrated that male pre-service mathematics teachers had higher mathematical sentences formation scores when compared to female pre-service mathematics teachers; however, the difference was not significant. This reason may be due to the familiarity of both genders pre-service mathematics teachers with context-based problems in the instruction process. The another reason for this may be that pre-service mathematics teachers were mixed in the same undergraduate education and encountered similar mathematics sentences formation. The preservice mathematics teachers within the scope of the research may have solved the context problems with similar mathematical sentences. The fact that pre-service mathematics teachers responded by evaluating the MoNE (2018) curriculum may be another reason for this results. Because, problem situations related to context-based learning were given in the secondary school mathematics curriculum published by the MoNE (2018) Board of Education and Discipline.

Analysis of the study results revealed that the juniors had the lowest and the freshmen had the highest problem-solving skills, and the mean context-based problem-solving scores differed significantly based on the class level. The calculated effect size indicated that the differences between the class levels were moderate. The analysis of the differences between class levels demonstrated that there was a significant difference between the freshmen and sophomores and between the freshmen and juniors, favoring the freshmen. Analysis of the effect size between the class levels with significant differences demonstrated that there was a moderate effect between these class levels. Results demonstrated that the sophomores exhibited the lowest and the freshmen exhibited the highest mathematical sentences formation skills. Furthermore, the achievements of freshmen and seniors in mathematical sentences formation skills were higher when compared to the sophomores and juniors. Analysis of the study data demonstrated that there were significant differences between the mean mathematical sentences formation scores of pre-service mathematics teachers based on the class level variable. Analysis of the significance of the difference between the class levels demonstrated that there were significant differences between the freshmen, sophomores and seniors, favoring the freshmen and seniors, respectively. Analysis of the effect size between the classes where the differences were significant demonstrated that the effect between the class levels was moderate. This may be explained by the fact that the freshmen have solved the problems more selflessly or have associated the problems better to daily life. Also, as the number of theory-based mathematics classes increases in undergraduate mathematics curricula, pre-service mathematics teachers may have moved away from daily life problems. This may be due to the development of mathematical sentences formation skills of pre-service mathematics teachers in their undergraduate education. Gilbert (2006) stated in study that cognitive level and experiences should be taken into account in the selection of contexts in teaching processes. Cetin (2014) reported that context-based learning and the contexts selected from daily life were different between the class levels. Yesildere (2006) reported that there were certain differences between the paths that the students follow in mathematical thinking and knowledge acquisition processes in different class levels.

Analysis of the study data demonstrated that male pre-service mathematics teachers have that they had less number of misconceptions when compared to female pre-service mathematics teachers; however, the difference was not significant. The reason for this may be that pre-service mathematics teachers have similar misconception knowledge thanks to the pedagogical field lessons they have taken. Esen and Ciftci (2000) reported that teachers exhibited misconceptions about learning disabilities. Yenilmez and Yasa (2008) stated that there was no significant difference between male and female based on mathematical misconceptions.

Analysis of the study data demonstrated that the sophomore students exhibited lower number misconceptions and the junior students exhibited the highest number of misconceptions. In general, it was observed that there was a significant difference between the mean pre-service teacher misconception scores based on class levels. The calculated effect size indicated that the differences between the effect sizes based on class levels were moderate. Analysis of the differences based on the class levels demonstrated that there were significant differences between the effect size based on the class levels favoring junior and senior students. Review of the effect sizes between the class levels between where the differences were significant demonstrated that the effects were medium and high between the class levels. This could be due to the fact that the pre-service mathematics teachers had a better understanding of misconceptions due to the previous pedagogy lessons and could predict the presence of this concept. Yenilmez and Yasa (2008) reported significant differences between the mathematical misconceptions exhibited by mathematical achievement classes. 
Based on Benckert's 2nd and 3rd principles, the evaluation scores of the pre-service mathematics teachers corresponded to "I Agree," while their context-based problems evaluation scores for all other principles and overall score corresponded to "I do not know" option. Furthermore, the scores for each principle and overall scores were above-average. The results conducted on the qualitative study data revealed three themes: cognitive skills, change in views, and conceptual or structural similarities. Six codes were determined in the cognitive skills theme, three codes were determined in the change in views theme and four codes were determined in conceptual or structural similarities theme. This could be due to the positive approach of pre-service mathematics teachers towards context-based problems based on Benckert's principles and their awareness about their cognitive skills and conceptual or structural similarities when expressing their views on the problems. Derman and Badeli (2017) reported that context-based instruction methods contributed to students' cognitive and affective learning areas. Binnie (2004) stated that context-based learning improved the interest of the students in the course. According to Güven and Karatas (2009), students' learning is more permanent in environments where the concept is structured within a context. Bennett et al. (2005b) emphasized that students who were instructed using context-based methods and learning were more enthusiastic and motivated and willing to take responsibility in learning. Anghileri (2000) stated that if students conduct operations using the numbers associated with a context, numbers and operations would be more meaningful for them.

\section{Limitations and Recommendations}

The study's sample group was limited to 114 pre-service mathematics teachers studying in an university's education department in the Southeastern Anatolia Region of Turkey. The topics covered in the study can be researched on larger sample groups from different regions. The study's content was limited to evaluating the solutions of the context-based problem situations according to Benckert's principles, mathematical statements, and misconceptions. Therefore, other concepts related to these elements can be researched in future studies. It was determined that the problem-solving and mathematical sentences formation skills of pre-service mathematics teachers were above average in context-based problems. Thus, to raise the awareness of preservice mathematics teachers in context-based problems, achievements or courses that include these types of problems could be included in undergraduate curriculum. Pre-service mathematics teachers stated that context-based problems would lead to some misconceptions. The types of misconceptions that may arise in these problems could be investigated with different analysis techniques in future studies. It was determined that pre-service mathematics teachers' attitudes to context-based problems were positive based on Benckert's principles. For this reason, context-based problems can be incorporated into middle school, secondary and undergraduate lessons to increase student awareness.

Author contributions: All authors have sufficiently contributed to the study, and agreed with the results and conclusions.

Author notes: A part of this study was presented as a abstract paper in "International Pegem Conference on Education (IPCEDU-2020)" on 1619 September.

Funding: No funding source is reported for this study.

Ethical declaration: The authors declare that they comply with all kinds of ethical rules. In addition, the participants approved the "Volunteer Participant Form".

Declaration of interest: No conflict of interest is declared by authors.

\section{REFERENCES}

Abramovich, S., \& Ehrlich, A. (2007). Computer as a medium for overcoming misconceptions in solving inequalities. Journal of Computers in Mathematics and Science Teaching, 26(3), 181-196.

Acar, B., \& Yaman, M. (2011). The effects of context-based learning on students' levels of knowledge and interest. Hacettepe University Journal of Education, 40(1), 1-10.

Almong, N., \& Ilany, B. S. (2012). Absolute value inequalities: High school students' solutions and misconceptions. Educational Studies in Mathematics, 81(1), 347-364. https://doi.org/10.1007/s10649-012-9404-Z

Anghileri, J. (2000). Teaching number sense. Cromwell Press.

Atilboz, N. G. (2004). 9th Grade students' understanding levels and misconceptions about mitosis and meiosis. Gazi University Journal of Education, 24(3), 147-157.

Aydogan, S., \& Gelbal, S. (2017). Examination of pre-service teachers' misconceptions in measurement and evaluation concepts. Journal of Measurement and Evaluation in Education and Psychology, 8(4), 404-420. https://doi.org/10.21031/epod.355275

Aylar, E. (2017). Inferences on the pedagogical content knowledge in the context of problem solving in the process of classroom teacher training. Mersin University Journal of the Faculty of Education, 13(2), 744-759. https://doi.org/10.17860/mersinefd.312232

Ayvacı, H. S., \& Coruhlu, T. S. (2009). Effects of explanatory stories on elimination of students' misconceptions about physical and chemical change. Ondokuz Mayis University Journal of Education Faculty, 28(1), 93-104.

Bahar, M. (2003). Misconceptions and strategies of change in biology education. Journal of Educational Sciences in Theory and Practice, 3(1), 30-64.

Baki, A., \& Bell, A. (1997). Secondary mathematics education (Volume I). YOK Publications.

Baltaci, S., \& Baki, A. (2017). The role of GeoGebra software in constructing a contextual learning environment: The case of the ellipse. Ahi Evran University, Kirsehir Journal of the Faculty of Education, 18(1), 429-449. 
Banoglu, K., \& Bas, Y. (2012). An investigation of students' perceptions of their sociology course in terms of the course's Importance, their social attainment and the learning environment. Journal of Education and Science, 37(164), 31-44.

Benckert, S. (1997). Context and conversation in physics education. Project Report 161-97, Swedish: Council fort he renewal of higher education.

Bennett J., Gräsel C., Parchmann I., \& Waddington D. (2005b). Context-based and conventional approaches to teaching chemistry: Comparing teachers' views. International Journal of Science Education, 27(13), $1521-1547$. https://doi.org/10.1080/09500690500153808

Bennett, J., Campbell, B., Hogarth, S., \& Lubben, F. (2005a). A systematic review of the effects of context-based and STS approaches in science teaching. In C. Kasanda, L. Muhammed, S. Akpo, \& E. Ngololo (Eds.), Proceedings of the 13th Annual Conference of the Southern African Association for Research in Mathematics, Science and Technology Education (pp. 53-58). Windhoak, Namibia.

Berns, R. G., \& Erickson, P. M. (2001). Contextual teaching and learning: Preparing students for the new economy. The Highlight Zone Research, 5(1), 1-8.

Bingham, A. (1998). Developing problem-solving skills in children (Translated by A. F. Oguzkan). Ministry of National Education(MoNE) Publications.

Binnie, A. (2004). Development of a senior physics syllabus in New South Wales. Journal of Physics Education, 39(6), 490-495. https://doi.org/10.1088/0031-9120/39/6/004

Buyukozturk, S., Kılıc-Cakmak, E., Akgun, O. E., Karadeniz, S., \& Demirel, F. (2016). Scientific research methods. Pegem Academy.

Cai, J. (2003). Singaporean students' mathematical thinking in problem solving and problem posing: An exploratory study. International Journal of Mathematical Education in Science and Technology, 34(5), $719-737$. https://doi.org/10.1080/00207390310001595401

Cetin, A. (2014). Daily life subjects that can be used with context-based learning in high school physics lessons. Journal of Educatıon Sciences Research, 4(1), 45-62. https://doi.org/10.12973/jesr.2014.41.3

Cheany, J., \& Ingebritsen T. S. (2005). Problem-based learning in an online course: A case study. Journal of International Review in Open and Distance Learning, 6(3), 123-140. https://doi.org/10.19173/irrodl.v6i3.267

Choi, H. J., \& Johnson, S. D. (2005). The effect of context-based video instruction on learning and motivation in online courses. The American Journal of Distance Education, 19(4), 215-227. https://doi.org/10.1207/s15389286ajde1904_3

Cohen, J. (1988). Statistical power analysis for the behavioral sciences (2nd ed.). Erlbaum.

Costu, B., Ayas, A., \& Unal, S. (2007). Misconceptions about boiling and their possible reasons. Kastamonu Education Journal, 15(1), 123-136.

De-Jong, O. (2006). Context-based chemical education how to improve it? Paper based on the plenary lecture presented at the 19th ICCE, Seoul, Korea, 12-17 August 2006.

Derman, A., \& Badeli, O. (2017). The investigation of the impact of the context-based teaching method supported by the 5e model in teaching 4th-grade students the "pure material and mixture" topic on the students' conceptual perceptions and their attıtude towards science. Abant Izzet Baysal University Journal of the Faculty of Education, 17(4), $1860-1881$. https://doi.org/10.17240/aibuefd.2017.17.32772-363969

Dikmenli, M., Cardak, O., \& Oztas, F. (2009). Conceptual problems in biology-related topics in primary science and technology textbooks in Turkey. International Journal of Environmental \& Science Education, 4(4), 429-440.

Elmas, R., \& Geban, O. (2016). The effect of context based chemistry instruction on 9th grade students' understanding of cleaning agents topic and their attitude toward environment. Education and Science, 41(185), 33-50. https://doi.org/10.15390/EB.2016.5502

Ernest, J. B., Reinholz, D. L., \& Shah, N. (2019). Hidden competence: women's mathematical participation in public and private classroom spaces. Educational Studies in Mathematics, 102(1), 153-172. https://doi.org/10.1007/s10649-019-09910-w

Eryilmaz, A., \& Surmeli, E. (2002). Measuring students' misconceptions about heat and temperature with three-step questions. V. National Science and Mathematics Education Congress, 16-18 September, METU, Ankara.

Esen, A., \& Ciftci, I. (2000). Determination of the knowledge of classroom teachers about learning disabilities. Pamukkale University Faculty of Education Journal, 8(1), 1-6.

Fechner, S. (2009). Effects of context-oriented learning on student interest and achievement in chemistry education (Vol. 95). Logos Verlag.

Gay, L. R., Mills, G. E., \& Airasian, P. (2006). Educational research: Competencies for analysis and application (8th ed.). Prentice Hall.

Gilbert, J. K. (2006). On the nature of 'context' in chemical education. International Journal of Science Education, 28(9), $957-976$. https://doi.org/10.1080/09500690600702470

Glynn, S. M., \& Koballa, T. R. J. (2005). The contextual teaching and learning instructional approach. In R. E. Yager (Ed.), Exemplary Science: Best practices in professional development (pp.75-84). National Science Teachers Association Press.

Gurbuz, R., \& Guder, Y. (2016). The strategies mathematics teachers use in problem solving. Ahi Evran University Journal of Kirsehir Education Faculty, 17(2), 371-386. 
Guven, B., \& Karatas, I. (2009). The effect of Cabri's dynamic geometry software on the success of elementary mathematics teachers in geometric ground problems. Ankara University Journal of the Faculty of Educational Sciences, 42(1), 1-31. https://doi.org/10.1501/Egifak_0000001135

Harskamp, E., \& Suhre, C. (2007). Schoenfeld's problem-solving theory in a student controlled learning environment. Journal of Computers \& Education, 49(1), 822-839. https://doi.org/10.1016/j.compedu.2005.11.024

Heller, P., \& Hollabaugh, M. (1992). Teaching problem solving through cooperative grouping. Part 2: Designing problems and structuring groups. American Journal of Physics, 60(7), 637-644. https://doi.org/10.1119/1.17118

Hiebert, J. (1986). Conceptual and procedural knowledge: The case of mathematics. Lawrence Erlbaum Associates.

Ilyas, A., \& Saeed, M. (2018). Exploring teachers' understanding about misconceptions of secondary grade chemistry students. International Journal for Cross-Disciplinary Subjects in Education, 9(1), $3323-3328$. https://doi.org/10.20533/ijcdse.2042.6364.2018.0444

Keskin, B., \& Ozay-Kose, E. (2017). Misconceptions of prospective biology teachers about theory of evolution. Necatibey Faculty of Education, Electronic Journal of Science and Mathematics Education, 11(2), $212-242$. https://doi.org/10.17522/balikesirnef.373344

Khumalo, L. T. N. (2009). A context-based problem solving approach in grade 8 Natural Science teaching and learning [Master's thesis, University of KwaZulu-Natal].

King, D. (2012). New perspectives on context-based teaching: Using a dialectical sociocultural approach to view teaching and learning. Studies in Science Education, 48(1), 51-87. https://doi.org/10.1080/03057267.2012.655037

Lubben, F., Campbell, B., \& Dlamini, B. (1996). Contextualizing science teaching in Swazilanf: Some student reactions. International Journal of Science Education, 18(3), 311-320. https://doi.org/10.1080/0950069960180304

Miles, M. B., \& Huberman, A. M. (1994). Qualitative data analysis. SAGE.

Ministry of National Education (MoNE) (2018). Mathematics course curriculum (Grades 1, 2, 3, 4, 5, 6, 7, and 8 in primary and secondary schools).

Noll, J., \& Hancock, S. (2015). Proper and paradigmatic metonymy as a lens for characterizing student conceptions of distributions and sampling. Educational Studies in Mathematics, 88(1), 361-383. https://doi.org/10.1007/s10649-014-9547-1

Olkun, S., \& Toluk, Z. (2009). Activity based mathematics education in primary education. Maya Academy.

Ozbellek, S. (2003). Confronted conceptions mistakes about angle, determination and elimination methods of deficient perceptions at 6 th and 7 th grades in primary education [Master's thesis, Dokuz Eylul University].

Ozsoy G., \& Ataman, A. (2009). The effect of metacognitive strategy training on mathematical problem solving achievement. International Electronic Journal of Elementary Education, 1(2), 67-82.

Passolunghi, M. C., Cargnelutti, E., \& Pellizzoni, S. (2019). The relation between cognitive and emotional factors and arithmetic problem-solving. Educational Studies in Mathematics, 100(3), 271-290. https://doi.org/10.1007/s10649-018-9863-y

Posamentier, A. S., \& Krulik S. (2008). Problem-solving strategies for efficient and elegant solutions, grades 6-12: A research for the mathematics teacher. SAGE.

Posamentier, A. S., \& Krulik, S. (2016). Problem-solving in mathematics, grades 3-6, Powerful strategies to deepen understanding. Corwin Press. https://doi.org/10.1142/9478

Programme for Internatıonal Student Assessment [PISA] (2018). Programme for Internatıonal Student Assessment Rapport.

Pugalee, D. K. (2001). Writing, mathematics, and metacognition: Looking for connections through students' work in mathematical problem-solving. School Science and Mathematics, 101(8), 236-245. https://doi.org/10.1111/j.1949-8594.2001.tb18026.x

Ryan, J., \& Williams, J. (2000). Mathematical discussions with children: Exploring methods and misconceptions as a teaching strategy. Centre for Mathematics Education, University of Manchester.

Ryve, A., \& Hemmi, K. (2019). Educational policy to improve mathematics instruction at scale: conceptualizing contextual factors. Educational Studies in Mathematics, 102(1), 379-394. https://doi.org/10.1007/s10649-019-09887-6

Schoenfeld, A. H. (2006). Mathematics teaching and learning. In P. A. Alexander \& P. H. Winne (Eds.), Handbook of educational psychology (pp. 479-510). Lawrence Erlbaum Associates Publishers.

Selvianiresa, D., \& Prabawanto, S. (2017). Contextual teaching and learning approach of mathematics in primary schools. International Conference on Mathematics and Science Education (ICMSCE), IOP Conf. Series: Journal of Physics: Conf. Series 895, 012171. https://doi.org/10.1088/1742-6596/895/1/012171

Senemoglu, N. (2018). Developmental learning and teaching. Ani Publishing House.

Sozbilir, M., Sadi, S., Kutu, H., \& Yildirim, A. (2007). Content/linking in chemistry education context-based teaching approach and its applications around the world. National Chemistry Education Congress, 20-22 June 2007.

Stinner, A. (1980). Physics, and the bionic man. The Physics Teacher, 18(1), 352-362. https://doi.org/10.1119/1.2340530

Tekbiyik, A., \& Akdeniz, A. R. (2010). An investigation on the comparison of context based and traditional physics problems. Necatibey Faculty of Education Electronic Journal of Science and Mathematics Education, 4(1), 123-140.

Toluk, Z., \& Olkun, S. (2002). Problem solving in mathematics education in Turkey: 1.-5. Grades math textbooks. Educational Sciences in Theory and Practice, 2(2), 563-581. 
Ubuz, B. (1999). Mistakes and misconceptions of 10th and 11th grade students in basic geometry. Hacettepe University Journal of Education, 17(17), 95-104.

Whitelegg, E., \& Parry, M. (1999). Real-life contexts for learning physics: Meanings, issues and practice. Physics Education, 34(2), 6872. https://doi.org/10.1088/0031-9120/34/2/014

Yagbasan, R., \& Gulcicek, C. (2003). Describing the characteristics of misconceptions in science teaching. Pamukkale University Journal of Education, 13(13), 102-120.

Yazici, T. (2014). Use and efficacy of problem-solving ability in beginner level piano education [PhD Thesis, Necmettin Erbakan University].

Yenilmez, K., \& Yasa, E. (2008). Primary school students' misconceptions about geometry. Uludag University Faculty of Education Journal, XXI(2), 461-483.

Yesildere, S. (2006). The investigation of mathematical thinking and knowledge construction processes of primary 6, 7 and 8th grade students who have different mathematical power [Master's thesis, Dokuz Eylul University].

Yildirim, A., \& Simsek, H. (2013). Qualitative research methods in the social sciences. Seckin Publishing.

Yurdakul, B. (2021). New trends in education. In O. Demirel (Ed.), Constructivism (pp. 39-40). Pegem Academy Publishing.

Zhu, Y., Kaiser, G., \& Cai, J. (2018). Gender equity in mathematical achievement: The case of China. Educational Studies in Mathematics, 99(1), 245-260. https://doi.org/10.1007/s10649-018-9846-z 


\section{APPENDIX 1}

\section{Contextual Problem Evaluation Form (CPEF)}

This study was developed to contribute to mathematics education based on your views as pre-service teachers interested in mathematics education. The results will be kept strictly confidential, will not affect your academic standing or grades. It is important to answer the questions sincerely to improve the accuracy of the study findings. Thank you for your answers.

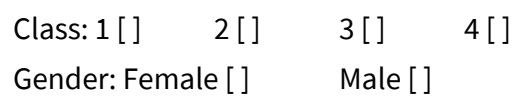

Question 1: A water well will be drilled to irrigate the green areas in your school. Since the ground water is found at 100 meters depth at that location, how many 7-meter long pipes should be used?

Answer:

Mathematical sentences formation:

Please indicate whether the problem given above was written based on contextual instruction by marking your views on each criteria presented in the table below: 1: I disagree, 2: I do not know, 3: I agree

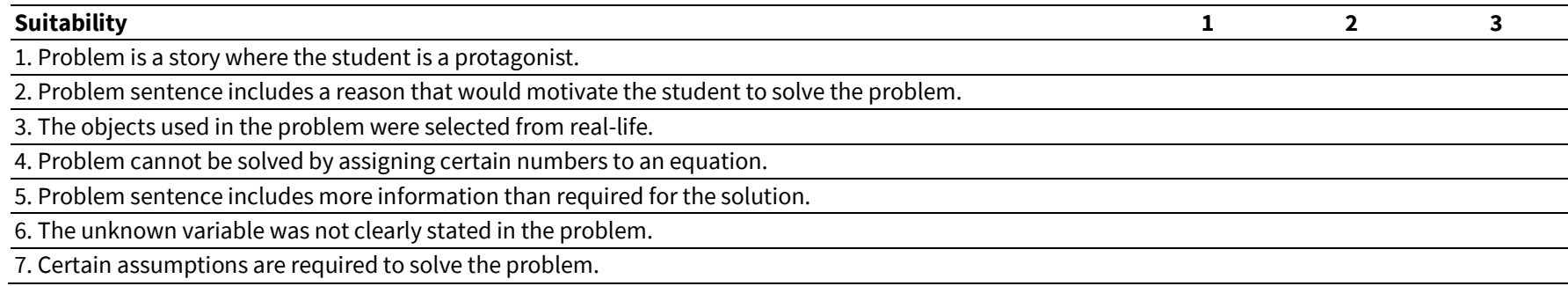

Question 2: A carpenter has 4 2.5-meter long laths. How many 1-meter long laths can the carpenter get from these?

Answer:

Mathematical sentences formation:

Please indicate whether the problem given above was written based on contextual instruction by marking your views on each criteria presented in the table below: 1: I disagree, 2: I do not know, 3: I agree

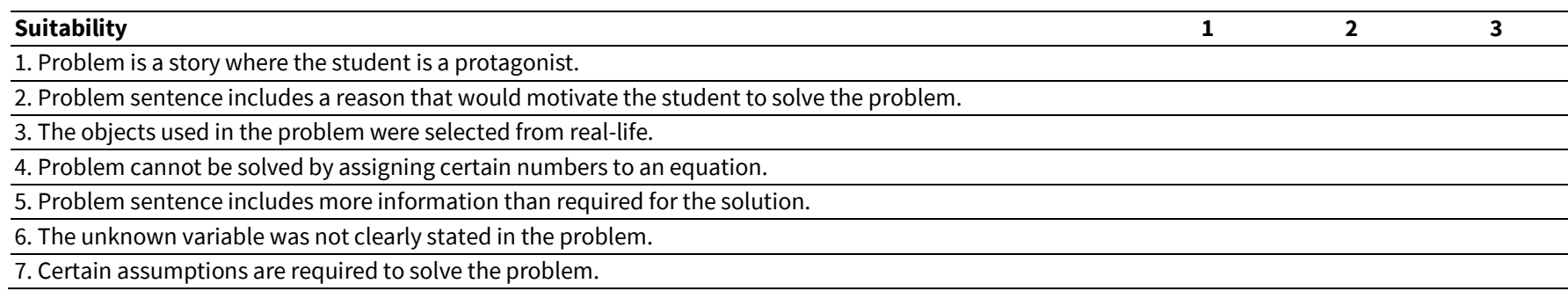

Question 3: A cable car line was constructed by the Ministry of Culture and Tourism from the city center to the post mountain in order to reach the post mountain where the tomb of the Prophet Zülküf is located at Ergani district in Diyarbakır province. The visitors' area at the Post Mountain could accommodate up to 100 guests and the cable cars used to access the mountain could carry 7 people on one ride. At least how many cars are required to carry the visitors?

Answer:

Mathematical sentences formation:

Please indicate whether the problem given above was written based on contextual instruction by marking your views on each criteria presented in the table below: 1: I disagree, 2: I do not know, 3: I agree

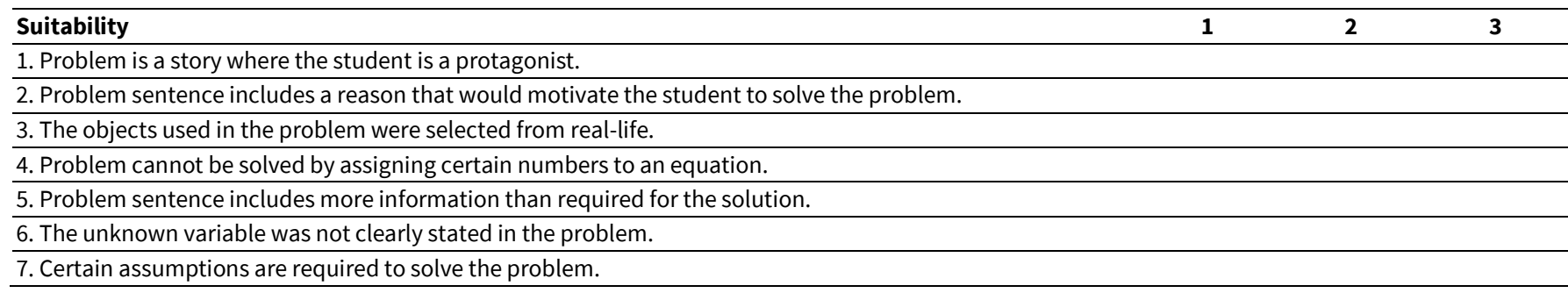


Question 4: An individual wants to place a washing line between two poles that are 12 meters apart. How many 2-meter long line pieces (s)he needs?

Answer:

Mathematical sentences formation:

Please indicate whether the problem given above was written based on contextual instruction by marking your views on each criteria presented in the table below: 1: I disagree, 2: I do not know, 3: I agree

\begin{tabular}{l}
\hline Suitability \\
\hline 1. Problem is a story where the student is a protagonist. \\
\hline 2. Problem sentence includes a reason that would motivate the student to solve the problem. \\
\hline 3. The objects used in the problem were selected from real-life. \\
\hline 4. Problem cannot be solved by assigning certain numbers to an equation. \\
\hline 5. Problem sentence includes more information than required for the solution. \\
\hline 6. The unknown variable was not clearly stated in the problem. \\
\hline 7. Certain assumptions are required to solve the problem. \\
\hline
\end{tabular}

Question 5: You have TL 100 cash and want to buy notebooks that cost TL 7 each. How many notebooks can you buy?

Answer:

Mathematical sentences formation:

Please indicate whether the problem given above was written based on contextual instruction by marking your views on each criteria presented in the table below: 1: I disagree, 2: I do not know, 3: I agree

\begin{tabular}{l}
\hline Suitability \\
\hline 1. Problem is a story where the student is a protagonist. \\
\hline 2. Problem sentence includes a reason that would motivate the student to solve the problem. \\
\hline 3. The objects used in the problem were selected from real-life. \\
\hline 4. Problem cannot be solved by assigning certain numbers to an equation. \\
\hline 5. Problem sentence includes more information than required for the solution. \\
\hline 6. The unknown variable was not clearly stated in the problem. \\
\hline 7. Certain assumptions are required to solve the problem. \\
\hline
\end{tabular}

Question 6: 100 specialist physicians, who work at the Dicle University, Faculty of Medicine outpatient clinic take their lunch in the dining hall located on the 10th floor of the faculty building using elevators, each of which can accommodate 7 people. What is the minimum time do the specialists need to use the elevator to reach the 10th floor at least?

Answer:

Mathematical sentences formation:

Please indicate whether the problem given above was written based on contextual instruction by marking your views on each criteria presented in the table below: 1: I disagree, 2: I do not know, 3: I agree

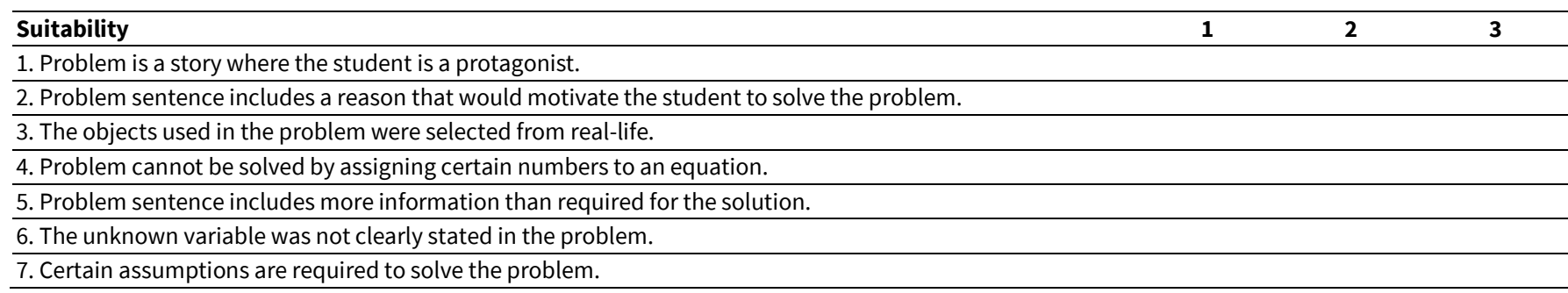

Question 7: Which question statement(s) could lead to misconceptions?

Answer: 


\section{APPENDIX 2}

\section{Structured Interview Form (SIF)}

Question 1: What do you think are the cognitive skills obtained in the CPEF study?

Question 2: Did your views on the point of the study change after the CPEF application?

Question 3: Are there differences between the questions 1, 3, 5, and 6 in CPEF (Please also indicate the questions that had conceptual or structural similarities.)? 